\title{
Repetition Rate of Partial Discharges in Low Voltage Cables
}

\author{
Richárd Cselkó1* \\ ${ }^{1}$ Department of Electric Power Engineering, Faculty of Electrical Engineering and Informatics, Budapest University \\ of Technology and Economics, H-1111 Budapest, Egry Jozsef utca 18., Hungary \\ * Corresponding author, e-mail: richard.cselko@gmail.com
}

Received: 23 May 2019, Accepted: 05 June 2019, Published online: 30 October 2019

\section{Abstract}

Diagnostic testing of low voltage cables by partial discharge measurement has several difficulties. One of them is that the cables are not designed to be partial discharge free at their test voltage. As partial discharge impulses may originate from numerous spots even in new cables, it is expected that impulses reach the termination with high repetition rate. The propagation of impulses in low voltage cables differs from the medium and high voltage cables; there is no lossy semiconducting layer or layers, but the cross section of the conductors are lower. The measurement method of partial discharges has to be adjusted to the discharge type and the propagation path as these determine the frequency content of the individual impulses, and the time resolution of the system has to be appropriate for the expected repetition rate. Measurements have been performed on various types of cables by different methods. Based on the results suggestions are given on the suitable measurement methods.
\end{abstract}

\section{Keywords}

partial discharges, low voltage cable, high-frequency current transformer, IEC60270

\section{Introduction}

The determination of the condition and possible damages of low-voltage cables is gaining importance, as they basically determine the safe operation of various critical systems [1-4]. Low-voltage cables are not designed to be partial discharge (PD) free at their test voltage, as the voids are not necessarily filled in their construction. Fig. 1 shows the electric field in a $5 \times 1.5 \mathrm{~mm}^{2}$ YSLCY type cable. The resulting electric field is high enough to initiate partial discharges, as detailed in [5].

As the electric field shown in Fig. 1 can initiate partial discharges at any point along the cable, relatively high repetition rates are expected, as shown in previous literature for similar but not identical arrangements [6-9]. Therefore, the applicability of the various detection methods need to be verified.

\section{Experimental}

Fig. 2 shows the measurement arrangement used in this study. Three PD detectors were used, a conventional measuring device complying the IEC 60270:2000 standard [10] and two high-frequency current transformers with different bandwidths.

The conventional measuring device, a Tettex 9120 detector [11] (later referred to as "IEC60270") has a bandwidth

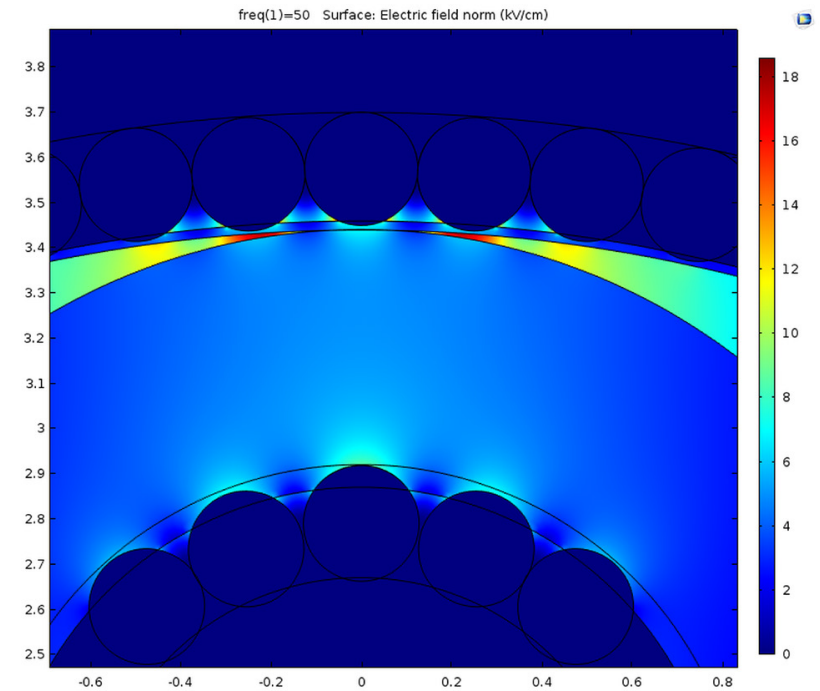

Fig. 1 Electric field within a $5 \times 1.5 \mathrm{~mm}^{2}$ YSLCY stranded core cable between the core and shielding at test voltage.

of $40 \mathrm{kHz}$ to $200 \mathrm{kHz}$, thus behaving as an integrating amplifier for the PD impulses. Accordingly, the output of the device is proportional to the charge carried by the impulses, thus it yields (pico-) coulombs. Wider bandwidth detectors gained popularity recently, as they might provide better signal-to-noise ratio and the possibility of locating 


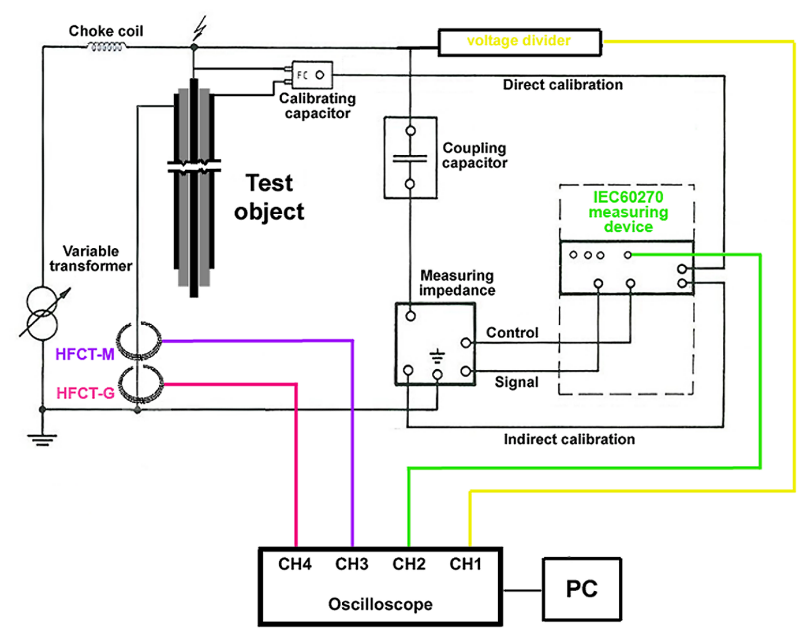

Fig. 2 Partial discharge measurement arrangement.

the impulses $[12,13]$. The first high frequency current transformer (HFCT) is a HVPD HFCT100/50 type detector [14] (later referred to as MHz HFCT or HFCT-M), specially designed to measure partial discharge signals on ground leads of power cables and electrical installation. The bandwidth is $100 \mathrm{kHz}$ to $20 \mathrm{MHz}$ and the rise time is $20 \mathrm{~ns}$. In case of higher voltage cables, this bandwidth is considered to give the most sensitive measurement [15-19]. The second HFCT is a very high bandwidth Tektronix CT - 1 [20] device (later referred to as GHz HFCT or HFCT-G), originally designed for measuring high frequency electronics, however, the measurement was arranged in a way that it enabled the application of this device. The bandwidth of this device is $25 \mathrm{kHz}$ to $1 \mathrm{GHz}$, with $350 \mathrm{ps}$ rise time. The two HFCTs were connected on the ground lead, measuring the same current, while the conventional devices used a coupling capacitor in series with its detection impedance.

The tests were performed on two base types of cables, and various test specimens were created to cover most of the features that are assumed to have an effect on the repetition rate:

- the two types have different conductor construction, the SzRMKVM-J has solid while the YSCLY has stranded cores

- investigated number of cores were 4,5 and 7,

- investigated cross-sections were $1.5 \mathrm{~mm}^{2}, 2.5 \mathrm{~mm}^{2}$ and $4 \mathrm{~mm}^{2}$,

- investigated lengths were $2 \mathrm{~m}, 8 \mathrm{~m}$ and $32 \mathrm{~m}$.

\section{Filtering the recorded signals}

In order to measure the small signals generated by the partial discharge impulses, very sensitive detectors are applied. This makes these methods prone to noise related problems. Accordingly, one of the most important tasks related to PD measurement is to establish a methodology that filters noise and respects the response of the measurement equipment. Our goal in this case is to estimate the number and frequency of discharges. Accordingly, signals coupled into the circuit (i.e. not showing the features of the response of the detectors) are filtered out, as well as the general noise level is determined.

\subsection{Filtering the IEC60270 signal}

The measuring device complying the IEC 60270:2000 standard [5] was originally not designed for further digital processing. The response of the device was intended to exhibit integrating behavior and to be satisfactory for internal processing by analog electronic methods. The response of the devices to a single PD impulse is damped wave, which may be oscillating or not. The devices most commonly used, including the one for this work, exhibit an oscillating response. Accordingly, for the sake of digital processing, e.g. to calculate the number of impulses, it is necessary to separate the individual impulses and delete the tail of the response.

The original, unfiltered response of the device is shown in Fig. 3.

The first step is the application of a digital filter matched to the bandwidth of the detector. The next step of the processing is to select the local maximums of the signal as shown in Fig. 4.

In case of the IEC60270 detector, the noise level was almost steady during the measurements; accordingly, a simple level-based filter was created. From this point, the absolute value of the signal was considered (Fig. 5).

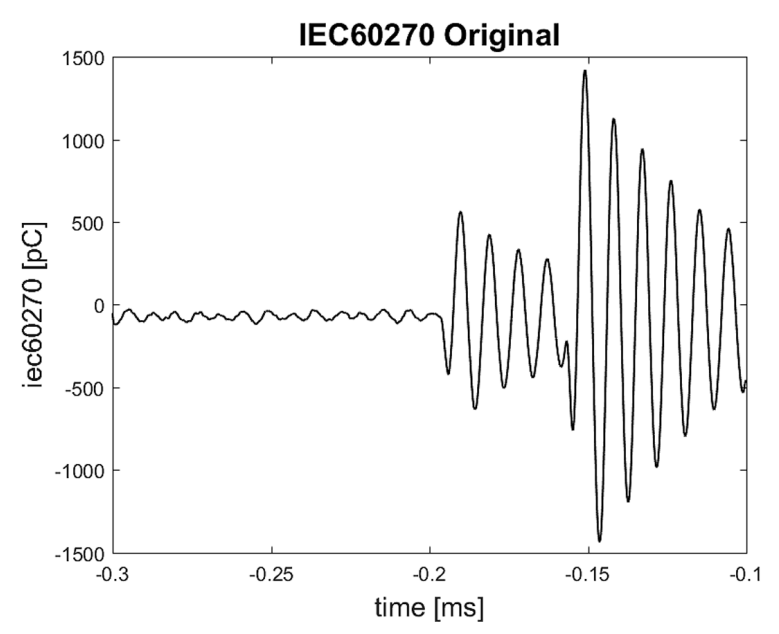

Fig. 3 Response of the conventional PD measuring device to two successive impulses as measured on the output. 


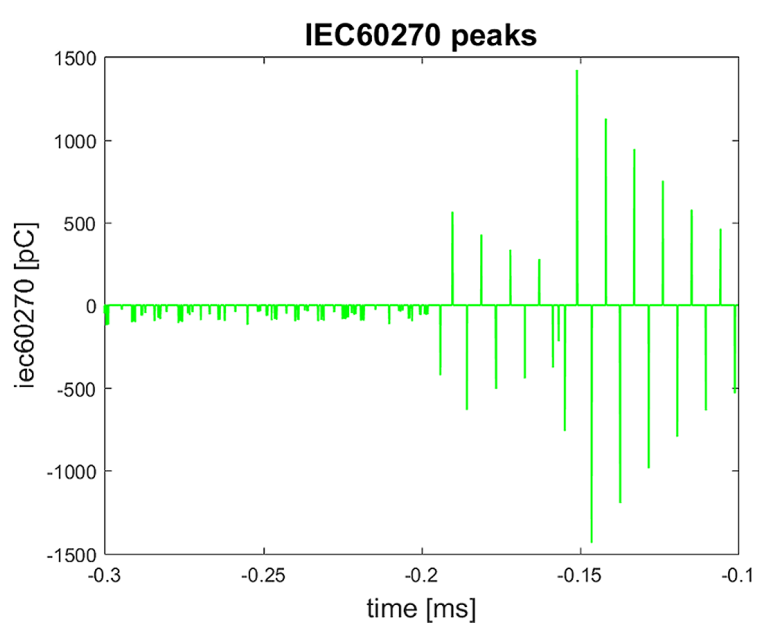

Fig. 4 Local maximums of the IEC60270 signal.

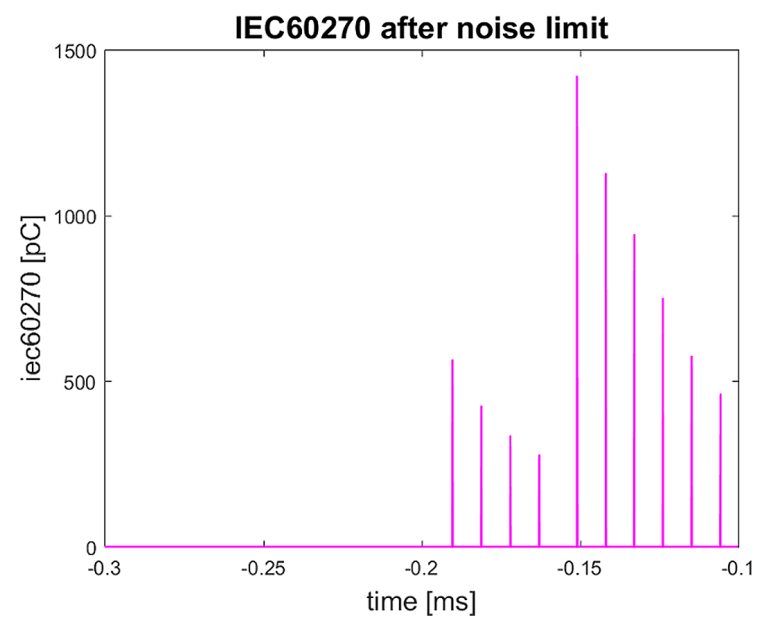

Fig. 5 The signal cleaned from the peaks below the noise level.

In the next step, the exponential damping of the response was taken into account. As there is no method to know if a peak is just the result of the oscillation of a previous impulse or a new impulse, the exponential damping was applied to all impulses (Fig. 6).

The rule of filtering can be written as:

$$
q_{i}<q_{N} e^{-\frac{\Delta t}{\tau}}
$$

where $i$ and $N$ are indices of peaks; $\Delta t$ is the time difference between the two peaks $\tau$ is the time constant of the response.

This method ensures that one PD impulse appears as one single peak in the final signal (Fig. 7). In order to save calculation time, the filtering has only been calculated for a limited number of successive impulses, namely until the right side of the equation falls below noise level. It has to be noted that an unavoidable error is introduced: if an impulse is followed by another impulse in a select

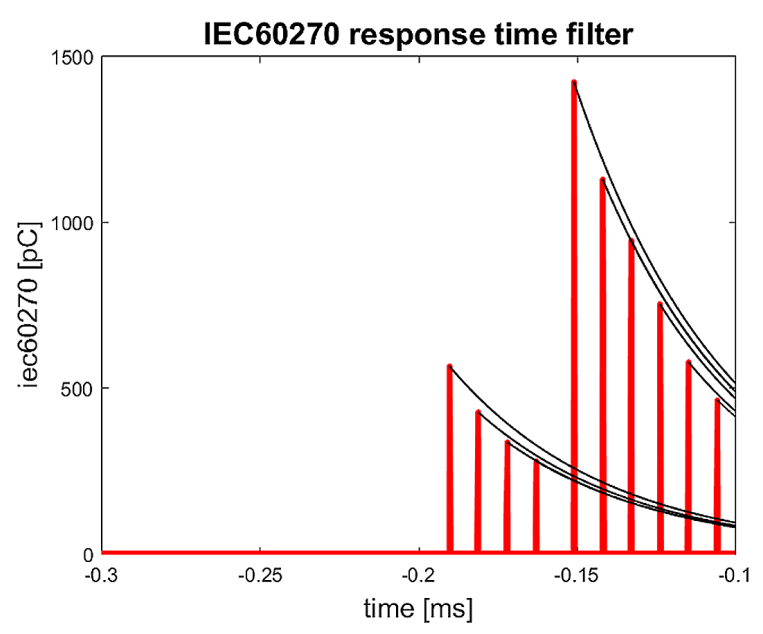

Fig. 6 Demonstration of the response time based filter.

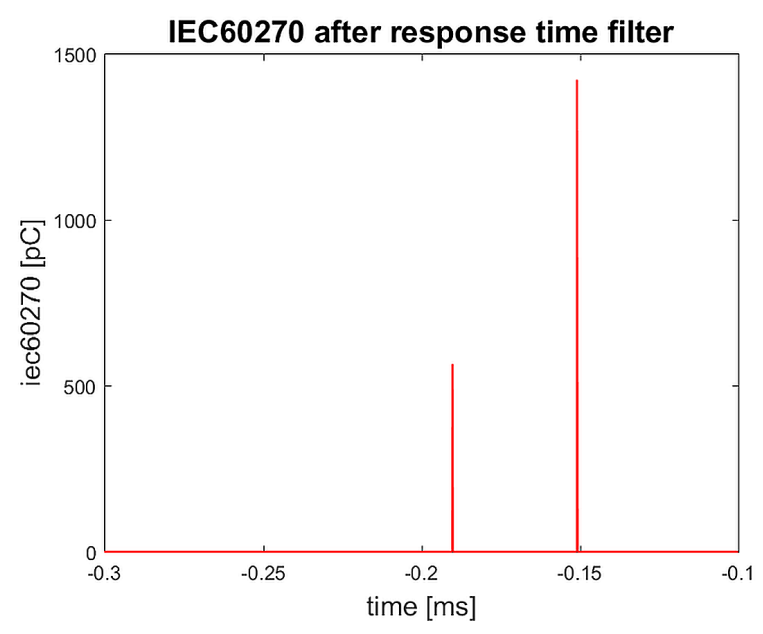

Fig. 7 Final signal after the complete processing.

combination of amplitude and time delay (phase), the algorithm might filter it out. However, this error is inherent in the measurement method and applies to the original analog readings of the device, as the same filtering is implemented electronically. The second impulse will be filtered if Eq. (4) inequality is fulfilled.

$R_{1}(t)=Q_{1} \sin (\omega t) e^{-\frac{t}{\tau}}$

$R_{2}(t)=\left\{\begin{array}{cc}Q_{2} \sin (\omega(t-\Delta t)) e^{-\frac{(t-\Delta t)}{\tau}}, & \text { for } t>\Delta t \\ 0, & \text { for } t<\Delta t\end{array}\right.$

$\operatorname{abs}\left(R_{1}(t)+R_{2}(t)\right)<Q_{1} e^{-\frac{t}{\tau}} \quad \forall t$

where $R_{1}(t)$ and $R_{2}(t)$ are the response of the detector to the first and second impulse, respectively; $\Delta t$ is the time difference between the two impulses; $\tau$ is the time constant of the response. 
Fig. 8 shows the relative amplitude - delay time combinations, where the detector rejects the second impulse.

As the time constant of the detector is around $50 \mu \mathrm{s}$, after $250 \mu$ s only very minor impulses are filtered. In contrast, if the successive impulse is close, it may even have higher amplitude if it arrives in opposite phase. This is the main reason why the application of high frequency current transformers with higher bandwidth and accordingly shorter response times may give more accurate results.

\subsection{Filtering the signal of the high frequency current transformers}

The processing of the HFCT signals also start with the FFT filter adjusted to the bandwidth of the sensor in question. As noise levels vary widely in the case of the HFCTs, the signals are filtered in two steps. In the first step, the impulses are augmented by calculating the convolution of the recorded signal with a pre-recorded sample of the response of the HFCT (Fig. 9).

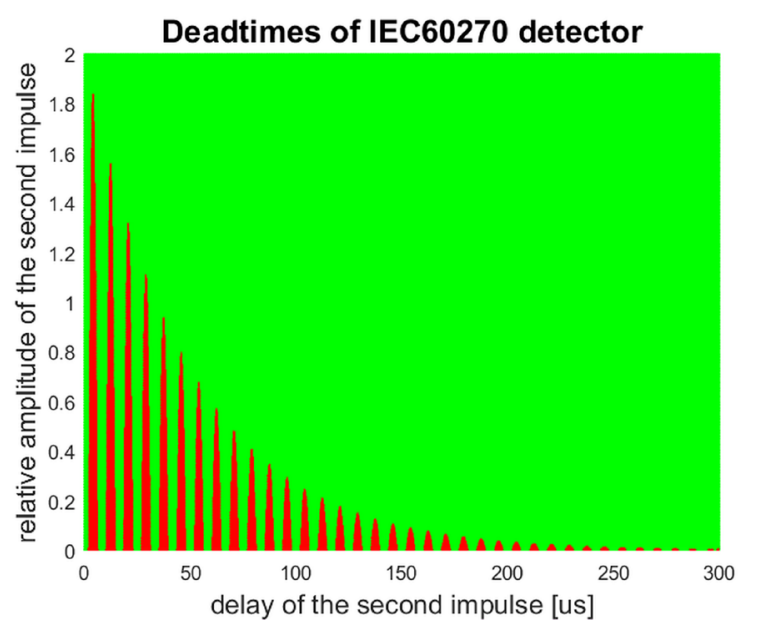

Fig. 8 Dead times of the IEC60270 detector, the delay-relative amplitude combinations in red are filtered out.

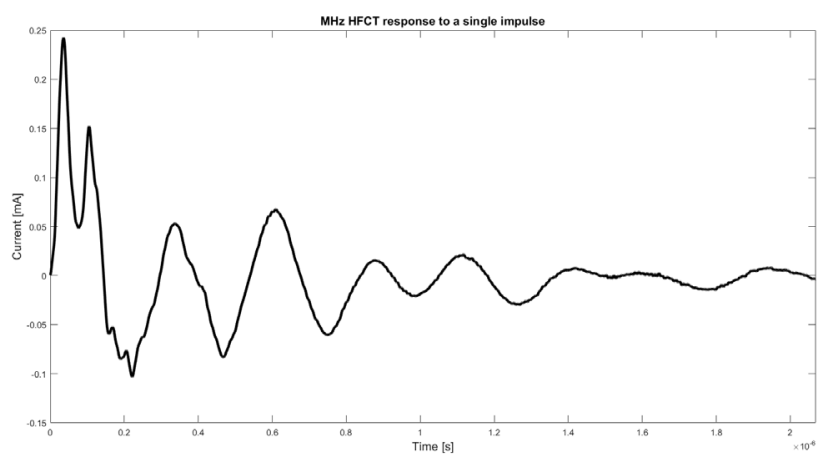

Fig. 9 Response of the MHz HFCT to a single impulse. Note the length of the response compared to the conventional detector ( $2 \mu \mathrm{s}$ vs. $250 \mu \mathrm{s}$ ).
After this step, the noise level was determined by the statistical distribution of the signal levels, using Eq. (5):

$i_{\text {noise }}=i_{\max }+2\left(i_{\max }-i_{\min }\right)$

where $i_{\max }$ is the most frequent signal level; $i_{\text {min }}$ is the lowest signal level.

The method can be followed in Fig. 10. The points in blue in the top image are filtered out. This level is shown by the red mark in the bottom figure (histogram of signal levels).

This is followed by a similar response time filtering, as shown for the case of the IEC60270 signal in Fig. 6.

\section{Repetition rate measurements on low-voltage cables}

In order to get insight into partial discharge repetition behavior, several measurements have been performed and evaluated.

Fig. 11 and Fig. 12 show the effect of the length of the cable.

Previous calculations have shown that partial discharges occur in low-voltage cables below their test voltage [4]. Assuming that the discharge locations are distributed evenly on a macroscopic scale, longer cables
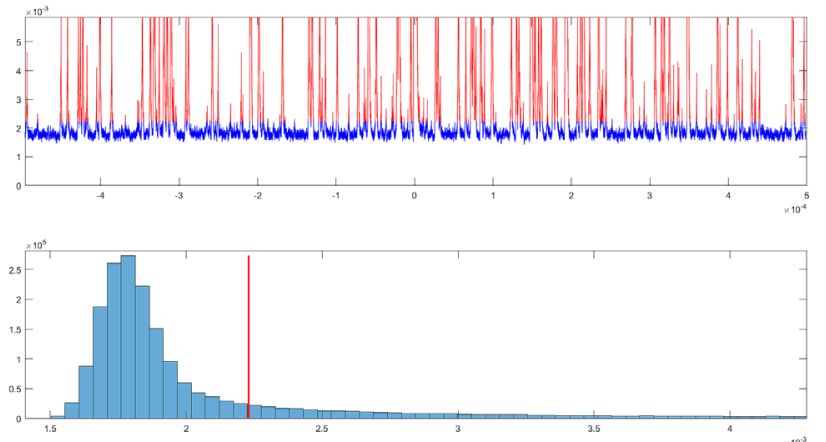

Fig. 10 The processed signal after convolution with the sample (top) and the histogram of the signal levels (bottom).

PD Repetition rate, solid core (MHz HFCT)

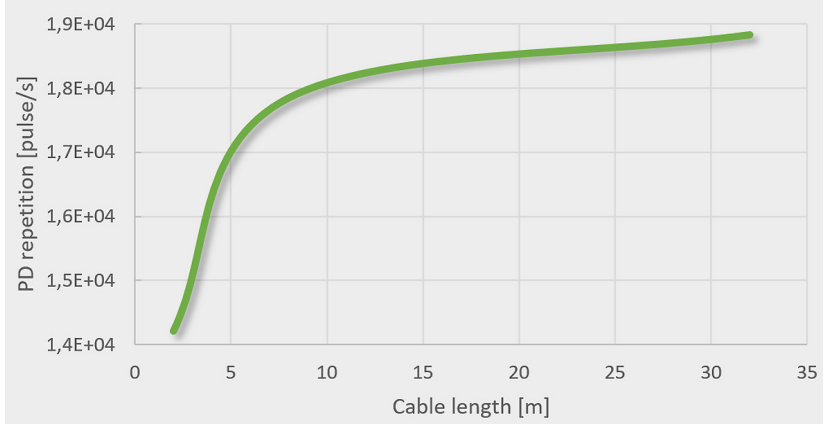

Fig. 11 Average repetition rate in function of cable length, solid core cable. 


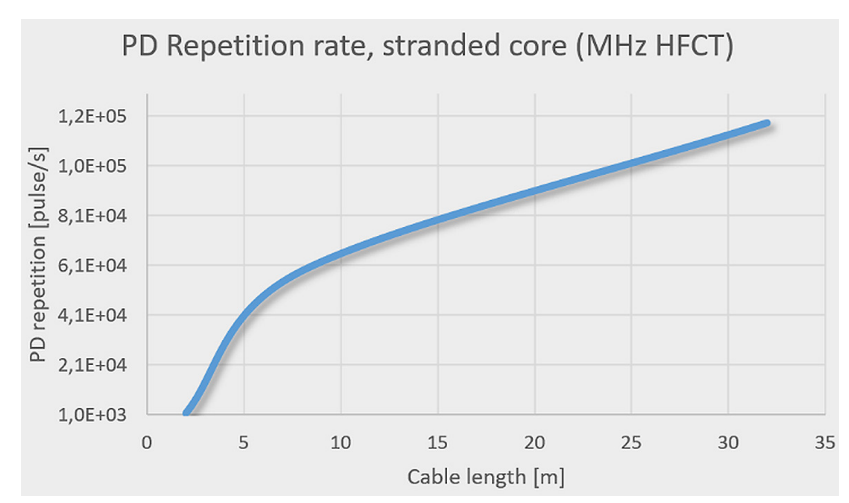

Fig. 12 Average repetition rate in function of cable length, stranded core cable.

should exhibit higher number of impulses. The measurement results are in line with this expectation, showing an increasing, but saturating curve.

The saturation is caused by the fact that in case of increasing number of discharges, the probability of two impulses overlapping increases. On the other hand, impulses on the far end of the cable are damped more, accordingly the apparent repetition rate is decreased by the number of low magnitude impulses.

The construction of the conductor, solid or stranded and core number do not show any trend (Fig. 13). In contrast, the repetition rate in the function of cross-section in case of 4 core cables exhibits the same behavior for solid and stranded core, a local maximum at $2.5 \mathrm{~mm}^{2}$ (Fig 14. and Fig. 15).

As the dimensions and conductor construction of the cables change, the effective area - where the electric field is above critical - changes, as well [4].

However, this is not necessarily a change, which shows a tendency in function of the aforementioned parameters. The constructions of the stranded cores change with

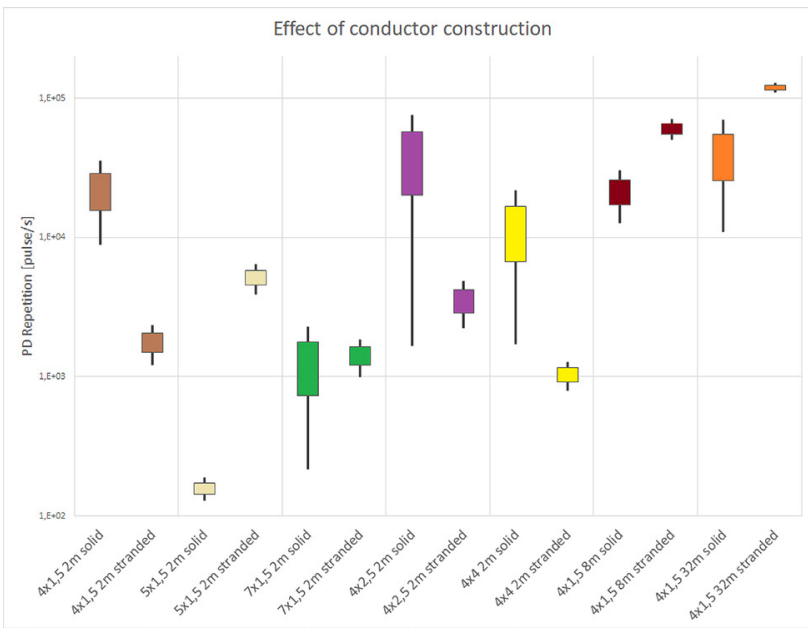

Fig. 13 Effect of conductor construction on the repetition rate.

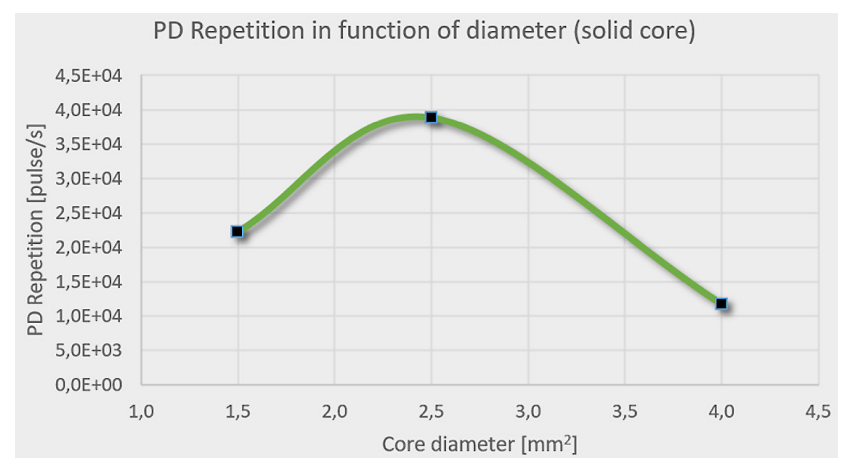

Fig. 14 Effect of conductor diameter, solid 4-core cable

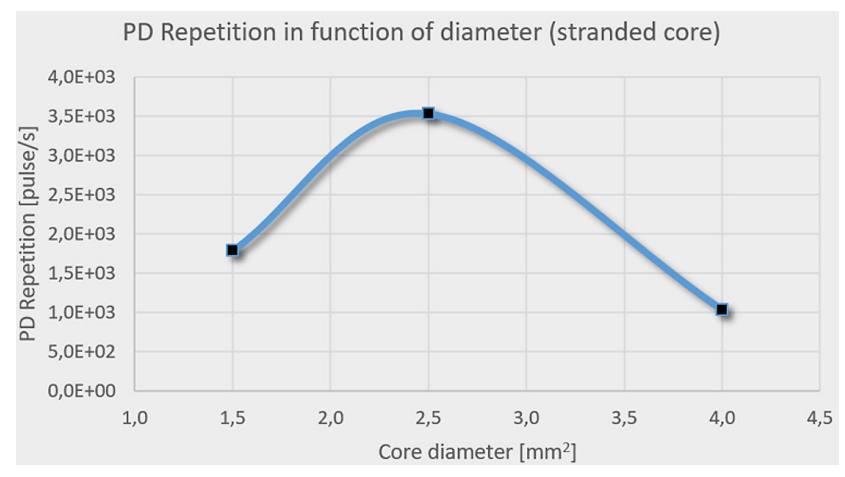

Fig. 15 Effect of conductor diameter, stranded 4-core cable

cross-section, as well. Therefore, the expected behavior has to be estimated based on electric field calculations, which goes beyond the scope of this paper.

\section{Discussion}

The results shown in the previous section are average repetition rates, i.e. the number of impulses recorded over more cycles of the test voltage and divided by the length of the sample. Even these average values are relatively high, considering the conventional measurement methodology.

The conventional detectors usually have a limited impulse response capability. This is mainly due to the demand of the integrating behavior and the bandwidth limitation in order to decrease the noise level. These detectors have an impulse resolution capability in the microsecond range, $5 \mu \mathrm{s}$ in case of the one used in these tests. The behavior of the detectors may be different in case of violation of the resolution:

- the detectors equipped with dead-time circuit underestimate the number of impulses, as the maximum repetition rate is limited to the reciprocal value of the dead-time,

- the detectors without dead-time overestimate the magnitude of the discharges, as they allow the successive impulses to superimpose, 
- any device might ignore impulses if they appear in specific moments.

Fig. 16 demonstrates these problems, where the abrupt changes in the response indicate that a new impulse superimposes on the response of a previous impulse. These occurrences are marked with arrows. The case marked with red arrow is an example when the two successive impulses are so close to each other in time that the response to the first impulse does not reach its first local maximum. Accordingly, the detector treats them as one larger impulse instead of two lower one.

In order to decide which detector is suitable and which is not, the actual time difference between the individual impulses has to be investigated. Fig. 17 shows the histogram of the time between impulses recorded at the same measurement for the three detectors. The two HFCTs show good agreement, while the IEC60270 device obviously ignored a high number of impulses that followed each other in close proximity.

\section{Conclusions}

In search of the appropriate partial discharge measurement method in low-voltage cables, the paper first discussed the detectors and signal processing methodology.

The compared detectors cover a wide range of bandwidth $(200 \mathrm{kHz}, 20 \mathrm{MHz}$ and $1 \mathrm{GHz}$ upper limit) and rise time or resolution ( $5 \mu \mathrm{s}, 20 \mathrm{~ns}$ and $350 \mathrm{ps}$ ). The paper demonstrates that low-voltage cables exhibit high repetition rates of partial discharge activity. Based on the histogram of the times between impulses it is concluded that the limits of the IEC 60270 detector are violated frequently,

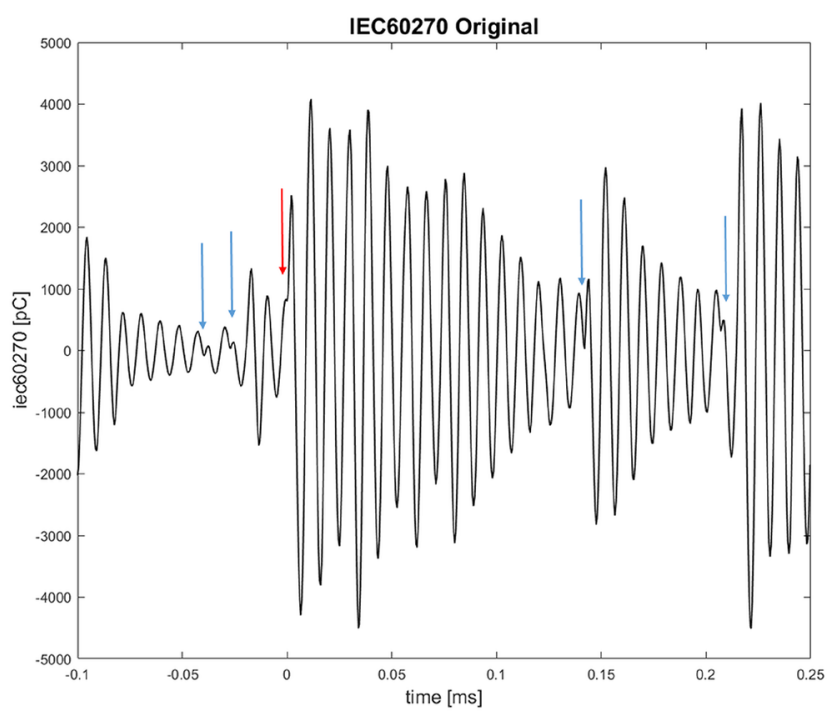

Fig. 16 Response of the IEC60270 detector in case of high repetition rate

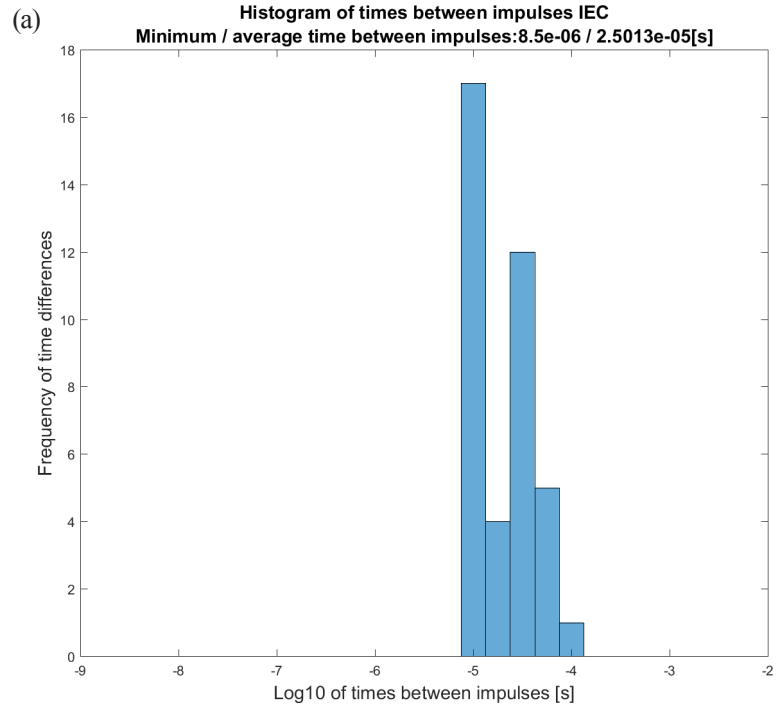

(b)
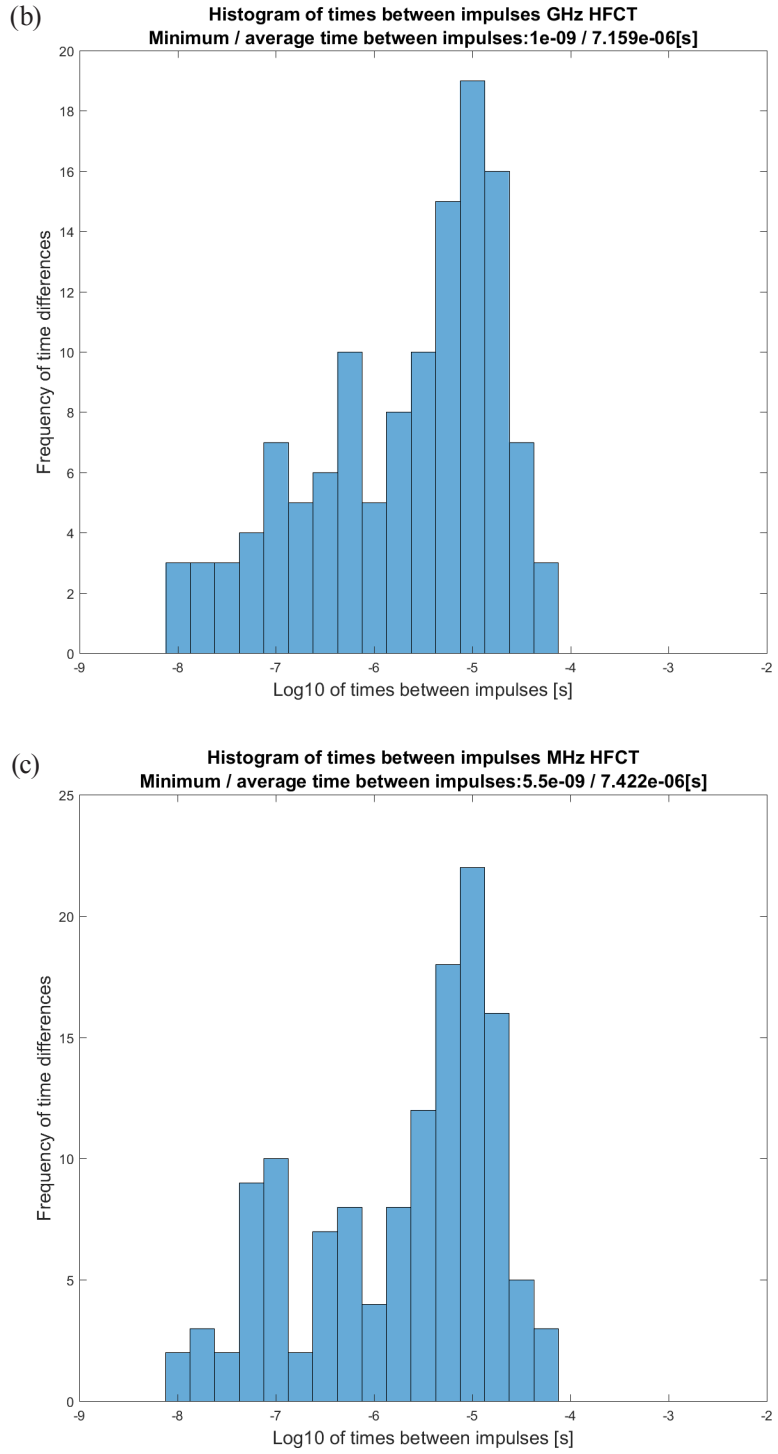

Fig. 17 Histogram of the times between impulses (a) IEC 60270 (b) MHz HFCT (c) GHz HFCT 
accordingly, its application is not recommended. The results of the two HFCTs show good agreement, thus the application of the $1 \mathrm{GHz}$ HFCT is not necessary, while the $20 \mathrm{MHz}$ HFCT is the most suitable detector for the measurement of partial discharges in low-voltage cables.

\section{References}

[1] Cselkó, R., Kiss, I. "Suppression of Conducted Disturbances During the Partial Discharge Monitoring of Industrial Cable Systems", In: Camarinha-Matos, L. M., Adu-Kankam, K. O., Julashokri, M. (eds.) Technological Innovation for Resilient Systems, IFIP Advances in Information and Communication Technology, Vol. 521, Springer Verlag, Cham, Switzerland, pp. 308-316, 2018.

https://doi.org/10.1007/978-3-319-78574-5_30

[2] Shumaker, B. D., Campbell, C. J., Sexton, C. D., Morton, G. W., McConkey, J. B., Hashemian, H. M. "Cable Condition Monitoring for Nuclear Power Plants", In: Future of Instrumentation International Workshop (FIIW), Gatlinburg, Tennessee, USA, 2012, pp. 1-4. https://doi.org/10.1109/FIIW.2012.6378325

[3] Kurek, J., Bernstein, R., Etheridge, M., LaSalle, G., McMahon, R., Meiner, J., Turner, N., Walz, M., Gomez, C. "Aircraft Wiring Degradation Study", Federal Aviation Administration, Washington, DC, USA, Rep. DOT/FAA/AR-08/2, 2008.

[4] Howard, R. K., Glover, S. F., Pena, G. E., Higgins, M. B., Schneider, L. X., Lockner, T. R. "Final Report on Development of Pulse Arrested Spark Discharge (PASD) for Aging Aircraft Wiring Application", Sandia National Laboratories, Albuquerque, New Mexico and Livermore, California, USA, Rep. SAND2005-2638, 2006.

[5] Cselkó, R., Kiss, I. "Estimation of the Partial Discharge Inception Voltage of Low Voltage Cables", In: 2019 IEEE Electrical Insulation Conference, Calgary, Canada, 2019. (in press)

[6] Cselkó, R., García, M. M., Berta, I. "Partial discharge characteristics of NYCY low-voltage cables", In: 2013 IEEE Electrical Insulation Conference (EIC), Ottawa, ON, Canada, 2013, pp. 138-141. https://doi.org/10.1109/EIC.2013.6554220

[7] Wang, L., Testa, L., Cavallini, A., Montanari, G. C. "Relation between the trend of partial discharges and aging models under AC voltage", In: 2009 IEEE 9th International Conference on the Properties and Applications of Dielectric Materials, Harbin, China, 2009, pp. 268-271.

https://doi.org/10.1109/ICPADM.2009.5252433

[8] Gulski, E., Koltunowicz W., Ariaans, T., Behrmann, G., Jongen, R., Garnacho, F., Kornhuber, S., Ohtsuka, S., Petzold, F., SánchezUrán, M. Á., Siodła, K., Tenbohlen, S. "Guidelines for partial discharge detection using conventional (IEC 60270) and unconventional methods", CIGRÉ Working Group D1.37, Technical Brochure Nr. 662, 2016.

[9] Martínez-Tarifa, J. M., Robles, G., Hombrados-Herrera, M. A. "Ageing study on enameled magnet wires through statistical analysis of conventional partial discharge magnitudes and repetition rate", In: 2016 IEEE International Conference on Dielectrics (ICD), Montpellier, France, 2016, pp. 650-653.

https://doi.org/10.1109/ICD.2016.7547699

\section{Acknowledgement}

This work has been supported by the ÚNKP-18-3 New National Excellence Program of the Ministry of Human Capacities.

[10] IEC "IEC 60270:2000 "High-voltage test techniques - Partial discharge measurements", International Electrotechnical Commission, Geneva, Switzerland, 2000.

[11] Tettex AG Tettex PD detectors Series 9120, Instruction Manual, Tettex AG, Zürich, Switzerland, 1993.

[12] Muhr, M., Schwarz, R., Pack, S., Koerbler, B. "Unconventional partial discharge measurement [electrical insulation evaluation]", In: The $17^{\text {th }}$ Annual Meeting of the IEEE Lasers and ElectroOptics Society, Boulder, CO, USA, 2004, pp. 430-433. https://doi.org/10.1109/CEIDP.2004.1364279

[13] Tian, Y., Lewin, P. L., Davies, A. E. "Comparison of On-line Partial Discharge Detection Methods for HV Cable Joints", IEEE Transactions on Dielectrics and Electrical Insulation, 9(4), pp. 604-615, 2002. https://doi.org/10.1109/TDEI.2002.1024439

[14] HVPD "HVPD On-Line Partial Discharge Sensors", User Manual, High Voltage Partial Discharge (HVPD) Ltd, 2009. [online] Available at: http://www.hvpd.co.uk/products/sensors/hfet-10050-portable.html [Accessed: 19 December 2009]

[15] Chandrasekar, S., Cavallini, A., Montanari, G. C., Puletti, F. "Bandwidth and Sensitivity Issues in PD Detection in Power Cables", IEEE Transactions on Dielectrics and Electrical Insulation, 14(3), pp. 735-743, 2007. https://doi.org/10.1109/TDEI.2007.369538

[16] Guo, J. J., Boggs, S. A. "High Frequency Signal Propagation in Solid Dielectric Tape Shielded Power Cables", IEEE Transactions on Power Delivery, 26(3), pp. 1793-1802, 2011. https://doi.org/10.1109/TPWRD.2010.2099134

[17] Montanari, G. C., Cavallini, A. "Partial discharge diagnostics: from apparatus monitoring to smart grid assessment", IEEE Electrical Insulation Magazine, 29(3), pp. 8-17, 2013. https://doi.org/10.1109/MEI.2013.6507409

[18] Stone, G. C. "Partial discharge diagnostics and electrical equipment insulation condition assessment", IEEE Transactions on Dielectrics and Electrical Insulation, 12(5), pp. 891-904, 2005. https://doi.org/10.1109/TDEI.2005.1522184

[19] Fenger, M., Hampton, R. N., Blandine, H., Densley, R. J., Plath, R., Balza, X., Tozzi, M., Pultrum, E., Sjoberg, M. L., Mashikian, M., De Clerk, Q., Cochet, F., Hansen, J. Z., Dhuiq, B., Montanari, G. C., Rakowska, A., Barclay, A., Ziegler, S., De Louredo, N., Testa, L., Colon, R., Yang, X., Nishiuchi, M. "On-site Partial Discharge assessment of HV and EHV cable systems", CIGRÉ Working Group B1.28, Technical Brochure Nr. 728, 2018.

[20] Tektronix "AC Current Probes: CT1 CT2 CT6 Datasheet", (document identifier: 60W-12572-4), Tektronix Inc., 2013. [online] Available at: https://www.tek.com/link-clickcount?url=https\%3A//download.tek.com/datasheet/AC_Current_ Probes.pdf\&nid=73041 [Accessed: 04 March 2019] 